\title{
Salvatore, Ricardo, La confederación argentina y sus subalternos: integración estatal, política y derechos en el Buenos Aires posindependiente (1820-1860), Centro de Investigaciones Diego Barros Arana, Santiago de Chile, 2020
}

Diecisiete años después, especie de secuela de Paisanos itinerantes: Orden estatal y experiencia subalterna en Buenos Aires durante la era de Rosas, ${ }^{1}$ Ricardo Salvatore nos propone reflexionar sobre la formación del Estado-nación en Argentina y las respuestas y experiencias de grupos subalternos a dicho proceso de naturaleza conflictiva. Centralizando su análisis en la provincia de Buenos Aires durante la era de Juan Manuel de Rosas, ya no son sólo objeto de estudio los peones de estancia y pequeños campesinos independientes, sino que versa en otros grupos: afro-porteños, pueblos indígenas, mujeres, unitarios comunes y vecinos rurales rebeldes. $\mathrm{Al}$ incorporar otros actores intenta entender mejor los múltiples entramados de poder y cómo fue la interacción particular de cada uno de ellos con las autoridades y una política estatal caracterizada por la ambivalencia entre coerción y persuasión.

Familiarizando al lector con el tema de análisis, empieza rescatando y resumiendo los principales aportes de Paisanos itinerantes... Recuperando sus voces, acciones y

\footnotetext{
* Universidad Nacional de Córdoba. E mail: santad087@gmail.com 1 Salvatore, Ricardo, Wandering Paysanos. State Order and Subaltern Experience in Buenos Aires Province during the Rosas Era, Duke University Press, Durham, North Carolina, 2003.
} 
\begin{tabular}{r|r} 
D. Santa & 26/27: pp.431-436 \\
Cuadernos de Historia. Serie economía y sociedad &
\end{tabular}

memorias a partir del análisis de las filiaciones elaboradas por las autoridades militares reclutadoras, reconstruye la experiencia colectiva de peones y campesinos que formaron parte del ejército y las milicias de la provincia de Buenos Aires.

Poniendo énfasis en la cuestión militar procede describiendo los intentos del Estado rosista por controlar y ordenar la campaña. Identifica las formas de coerción y estímulos aplicados por el Estado en las unidades militares como también las estrategias de resistencia y de negociación que desarrollaron los subalternos. Entre ellas, la deserción y sus consecuentes acciones para no ser capturados, es decir, forjar una nueva identidad social y poder asentarse en una localidad. Dimensiona qué incidencia tuvo el servicio militar no sólo en la experiencia vivida sino también en nociones de pertenencia territorial e idea de nación que pudieron construir los soldados en sus participaciones bélicas en y fuera de la provincia. Esto le permite discutir con la historiografía tradicional hasta qué punto las autonomías provinciales fueron las principales protagonistas para modelar los sentidos de pertenencia de la población. Con los avances logrados puede desarrollar su concepto de "patriotismo condicional" y las formas de federalismo practicadas.

Identificados por Salvatore como "subalternos integrales", porque pese a su condición no dejaron de considerarse parte integrante de la patria federal, en este capítulo se examina el papel que tuvieron las y los afro-porteños en la construcción del orden rosista. Sustentado en el análisis de la poesía federal negra, de documentos de archivos estatales, de periódicos y de pintura de época, el autor refiere a un proceso que llama la "larga agonía de la esclavitud". En ello, rescata sus voces, sus intervenciones políticas y un conjunto de tácticas a través de las cuales lucharon por libertad, respeto y otras garantías individuales.

Comienza contrastando los avances historiográficos de los últimos veinte años con las obras de los intelectuales románticos y positivistas que muestran a los y las afroporteñas como agentes o instrumentos de un régimen opresor y tiránico. Desarrolla las condiciones de la esclavitud en Buenos Aires que facilitó la disminución y posterior desaparición de la misma, donde se resalta el concepto de "esclavitud estipendaria" y las dificultades para establecer una "línea de color". La utilización de la poesía le permite al autor evidenciar las formas y el grado en que se expresaron negros y negras a la causa federal, relacionándola con las medidas de gobierno que 
incidieron con el fin de la esclavitud. Otros aportes son las diversas formas de resistencia cotidianas desplegadas por los morenos (esclavos, libertos y libres) y la política militar de Rosas en relación con ellos.

En base a la lectura de cartas, informes militares, tratados, diarios de protagonistas y sumarios criminales, se aborda la relación entre el Estado rosista y los pueblos indígenas. El Estado tuvo una política dual, basada en una peculiar concepción del castigo y la aculturación, que combinaba amistad con terror que Salvatore denomina "invitación violenta". El autor por un lado expresa las conflictivas relaciones entre Estado y sociedad indígena: malones, expediciones punitivas, negociaciones, tratados de paz, trueque y compraventa de cautivos y cautivas. Por otro lado, el derrotero de los indios como individuos, sus estrategias y sus dificultades para incorporarse a la sociedad cristiana en un marco de relaciones forjadas por las partes, bajo el miedo y la ambivalencia de aceptación y rechazo. Concluye que en todos los aspectos para los pueblos originarios, el saldo fue negativo ya que sufrían violencia tanto si se incorporaban a la sociedad criolla como también si se resistían y continuaban maloqueando.

Con respecto a la mujer pobre, campesina y federal, se propone rescatar su voz en un contexto de guerra civil y fuerte conflictividad. En consonancia con los resultados de la historiografía reciente desarrolla una mirada de la mujer que discute con otra historiografía atada a las nociones de familia tradicional, patriarcado y domesticidad. Es por ello que revisa el testimonio de los viajeros extranjeros y los escritos de los intelectuales unitarios y federales que, bajo una mirada sesgada, terminan dando cuenta de un ideal de mujer más que de mujeres reales que defendían sus respectivas causas. Con el análisis de datos fragmentados y recortes de voces extraídos de fuentes novedosas como sumarios criminales, peticiones, correspondencia, filiaciones, denuncias de la curia, relatos sobre festividades públicas y literatura gauchi-política se pone en búsqueda de esa mirada real. Describe diversas experiencias: la conflictiva presencia de las mujeres en los lugares de producción y del ámbito militar, la violencia de género a la que estaban sujetas y las formas de proceder con el sexo opuesto consideradas inmorales para la Iglesia y las autoridades. En todos estos casos, esta actriz social no tiene una actitud pasiva tal como se observa con las peticiones hacia el gobernador para que los derechos de sus esposos e hijos 
militarizados sean respetados. Por último, se aborda el rol activo que tuvieron en la política facciosa que incluso fue alentado por los publicistas del rosismo.

Es interesante y jugada la propuesta de Salvatore sobre los unitarios ya que discute y completa la mirada tradicional que siempre los caracterizó como un grupo de intelectuales u oficiales ilustrados. Diferenciados los "unitarios comunes" de aquellos pertenecientes a las elites, trabaja cómo cada uno de ellos vivenció y enfrentó los embates del Estado rosista y la experiencia de la guerra civil. El capítulo se organiza en tres partes: primero, la construcción del unitario como enemigo público describiendo las significaciones y usos que hacían los federales del concepto y su tratamiento con amenazas de exterminio, insultos, expresiones festivas y elaboración de listas y clasificaciones. Segundo, las formas de resistencia cotidianas del que Salvatore denomina "unitario pacífico". Tercero, la comprensión de los valores y las motivaciones tanto de los soldados unitarios como de sus oficiales analizando el derrotero de los primeros en la guerra y sus conflictos con sus superiores. Utiliza como fuentes la correspondencia entre autoridades y las filiaciones y clasificaciones de soldados, desertores y delincuentes.

El último apartado de subalternos está dedicado a la rebelión del coronel Hilario Lagos y al correspondiente sitio que impuso a la ciudad de Buenos Aires entre diciembre de 1852 y julio de 1853. Se trató de un levantamiento de vecinospropietarios que involucró una veintena de pueblos de la campaña contra la decisión del gobierno de Buenos Aires de no participar en el Congreso Constituyente de Santa $\mathrm{Fe}$ y desconocer a Justo José de Urquiza como director provisorio de la Confederación Argentina. Para el autor, estos rebeldes representaron un punto de vista y discurso suprimido durante la hegemonía del federalismo rosista, como también, una relación problemática con el concepto de subalternidad ya que los campesinos constitucionalistas "rebeldes de Lagos" no pertenecerían a esta condición, aunque el tratamiento que hicieron sus enemigos antes y después de la rebelión, si lo fue.

Como estrategia metodológica, analiza el discurso y la retórica de la rebelión desde la perspectiva de ambos bandos. Para ello discute con la mirada del historiador militar unitario José L. Bustamante que considera a la rebelión como un hecho bárbaro producto de la asociación de campesinos ignorantes, débiles y de fácil persuasión por 
caudillos despóticos. En contrapeso a dicha mirada trabaja con las actas de apoyo a la rebelión que circularon de un pueblo a otro para descomponer los elementos constituyentes del discurso político e ideológico de estos documentos. A partir de ellos describe la posición política de los rebeldes en relación a la constitución, al rol que había cumplido Buenos Aires en la etapa del rosismo y las causas por las cuales debía esta provincia incorporarse a la nación. Ya sea peleando militarmente, delegando la dirección en Hilario Lagos o eligiendo diputados para conformar una convención provincial que discutiera la Constitución de la Confederación, los rebeldes para justificar sus decisiones y acciones abogan por un principio de sustento político usado en el pasado: la "retroversión de la soberanía". Durante su exposición, el autor hace algunas preguntas que no puede responder por la falta de información en las actas y en la bibliografía con la que trabaja pero que, sin embargo, invitan a la reflexión.

En la conclusión general del libro se desarrollan los principales aportes del trabajo con los actores analizados. Sostiene el concepto de "subalternidades múltiples" señalando que la relación entre Estado y subalterno es particular a cada uno de ellos. Dedica un apartado al trabajo con la información, donde la segmenta en dos grupos: por un lado, la "prosa de la contrainsurgencia" - es decir lo que decían las clases dominantes de ellos; por otro, las voces subalternas recatadas de los documentos en los archivos estatales. Terminando, argumenta por qué sostiene que la Confederación rosista fue una república inacabada y fragmentada. Finaliza haciendo una reflexión sobre la relación de estos actores con el Estado siguiente a la caída de Rosas, gobernado por sus enemigos públicos.

El trabajo del autor es valioso porque desentraña actores subalternos de los cuales resta mucho por investigar. El uso de una vasta bibliografía y material de archivo es un punto fuerte a la vez que la metodología implementada lo hace un material de consulta para todos aquellos interesados en trabajar subalternidad. Pese a que señala que han sido pocos los estudios de América Latina que han seguido la programática original de los historiadores subalternos indios, él la respeta: rescatar al subalterno y darle su lugar en la historia del colonialismo y la emancipación nacional; además de utilizar las principales herramientas hermenéuticas heredadas de este grupo. 
Para el lector, la información se presenta bien estructurada y la redacción es sencilla lo cual lo convierte en un trabajo de interés para un público extra académico. A veces sin que se vuelva confuso, cae en la repetición de conclusiones e hipótesis. Es común encontrarse con numerosas preguntas de investigación y con momentos de sinceridad por parte del historiador cuando deja en claro que ciertas cuestiones no las ha podido responder.

Los avances logrados alientan a los historiadores a desarrollar estos temas no sólo en Buenos Aires sino en otros territorios que pertenecieron a la Confederación Argentina. Tanto en esta investigación como en Paisanos itinerantes... Ricardo Salvatore confirma que desplegando en el oficio técnicas exhaustivas, inteligentes y creativas, los subalternos pueden hablar. 